\title{
Developing performance management systems for the green supply chain
}

\author{
Michael Mutingi ${ }^{1,2^{*}}$, Herbert Mapfaira $^{1}$ and Robert Monageng ${ }^{1}$
}

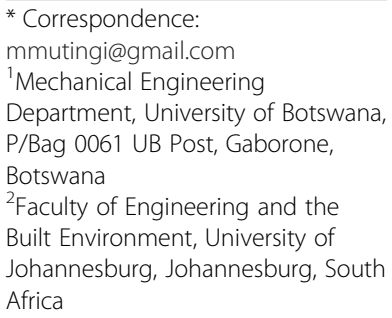

\begin{abstract}
As 'green' issues continue to become a global concern in the manufacturing supply chain, developing appropriate performance measurement systems for specific supply chains is imperative. Various green supply chain management strategies have been proposed in different contexts. On the other hand, a number of performance management systems (PMS) have been proposed. However, given the variations in the contexts of the available green strategies and the performance measurement approaches, selecting or developing suitable performance measures and the ensuing PMS under a given supply chain context is not trivial. The purpose of this study is to develop a structured taxonomic approach to developing PMS under various green supply chain conditions, contexts, and business objectives. Therefore, we (i) explore extant empirical studies on green supply chain activities and environmental management, (ii) develop a taxonomy of green supply chain strategies, (iii) derive a structured approach to developing green performance management systems, and (iv) provide a taxonomic performance measurement framework consisting of environmental, economic, and social performance metrics. Unlike past studies, the taxonomic framework forms a practical platform to assist decision makers when developing a suitable set of performance measures and the ultimate PMS while considering the particular context of specific green strategies under which the PMS is supposed to operate.
\end{abstract}

Keywords: Green supply chain; Performance management systems; Performance measurement; Environmental management

\section{Introduction}

As environmental issues are rapidly becoming one of the most important topics in supply chain management, managers consider improvements in environmental or 'green' performance a basic competitive priority besides lower cost, short lead time, and high quality [1-3]. The ever-growing green concerns in the market place and the ensuing green movements have forced decision makers to manage their organizational performance from the ecological or environmental perspective. Business activities can have an impact on the natural environment through one or more of the following ways:

- Emissions to air, e.g., greenhouse gases, dust and particles, metal emissions to air, ozone depleting substances

- Emissions to water, e.g., waste water, metal emissions to water

(c) 2014 Mutingi et al.; licensee Springer. This is an Open Access article distributed under the terms of the Creative Commons Attribution License (http://creativecommons.org/licenses/by/4.0), which permits unrestricted use, distribution, and reproduction in any medium, provided the original work is properly credited. 
- Emission to land, e.g., pesticides and fertilizers, metal emissions to land, radioactive waste

- Resource use, e.g., water use and abstraction, minerals, forestry

In various countries, regulatory bodies enforce recovery of product packaging [4]. A number of automotive industries have introduced product take back, recycling and reuse policies [5]. The introduction of green strategies for environmental management bears a significant impact on the choice and successful implementation of a performance measurement system. In this connection, it can be seen that linking specific green strategies to appropriate performance measurement systems is a serious challenge to most supply chain decision makers. Precisely, the implementation of green strategies requires changes in performance management in one or more of the following problem areas $[1,6]$ :

- Procurement policies: New environmental performance requirements often demand significant modifications in materials and supply procedures;

- Product technology: The introduction of new environmental targets often demands new product structure in relation to design, components, and materials;

- Process technology: Environmental strategies often require new technologies, e.g., closed-loop and cleaner technologies with reduced environmental impact;

- Logistics and distribution: Environmental policies may require new ways of managing physical flows of goods and collaboration with other players in the supply chain.

Remarkable extant studies on the strategic importance of green issues and green performance management systems (PMS) are vast [1,2,7-10]. Most researchers and practitioners have focused their attention on two major study areas, namely (i) analysis of green strategies available to supply chain managers and ways of enhancing strategy formulation [1,2], and (ii) development of frameworks for assessing organizational environmental performance based on physical indicators [4], environmental costs [11], and life-cycle assessment methods [7]. Gunasekaran et al. [8] investigated issues concerned with current practices in supply chain performance measurement systems, providing insights into the future requirements in supply chain performance measurement. The main issues discussed include (i) the need for organization-wide and supply-chain-wide integration and coordination; (ii) the need for every metric to take a supply chain perspective in order to monitor performance effectively; (iii) the need for a common goal upon which each entity in the supply chain is measured and improved; and (iv) the need for designing additional new indicators, non-financial and financial, to cater for new developments in the supply chain context. As pointed out by Brewer and Speh [9], there are a number of concerns associated with the development and application of performance measurement systems across the entire supply chain. Some of these issues are outlined as follows [9]:

- Lack of understanding: Managers that are focused on internal systems find it difficult to understand the importance of multi-organizational performance measures or indicators; 
- Lack of control: Most organizations and decision makers prefer to be evaluated on indicators they can control; without sufficient supply chain collaboration, the management and control of inter-organizational indicators is complex;

- Different goals and objectives: Organizations have different goals and objectives, therefore would argue on the selection of performance indicators;

- Lack of standardized performance indicators: In most supply chains, there are no agreed-upon performance measures in terms of units to use, structure, and format; and

- Difficulty in linking measures to stakeholder value: Linking measures to stakeholder or customer value and environmental issues is becoming more and more complex.

Besides the above-mentioned body of literature and the issues arising, there is continual research activity in the development and application of performance measurement and management systems, for both conventional and green supply chain systems. This demonstrates the ever-increasing importance of developing the right PMS system for the right supply chain. Surprisingly, most of these studies tend to propose these PMS from a general point of view $[1,2,7]$. On the contrary, the main benefit of this study is that it proposes green performance management frameworks that will be able to assist managers to know how to evaluate their organizational green performance taking into consideration both the constraints of their supply chain network, organizational pressures, and objectives of the business.

Also in spite of growing literature on these issues, little attention has been paid to the design and implementation of environmental performance measurement systems that take into account the specific context of green strategies, from a taxonomic view point. The concerns pointed out above stem from the fact that there are a number of green strategies and performance management tools and systems that can be applied in different contexts of the green supply chain strategies used. Moreover, different firms have different organizational objectives and capabilities. As such, the development of an appropriate performance system, given the right green strategy, is not a trivial task. In view of these issues, the design of a carefully defined framework for the development of effective performance measurement systems is imperative. Most of the frameworks in the green supply chain literature simply classify green strategies into reactive and proactive strategies, which is rather too broad $[7,8,10]$.

Numerous extant studies dealt with traditional supply chain performance metrics without consideration of the environmental performance. The traditional supply chain only deals with indicators associated with cost, time, quality, and flexibility [8-10,12]. On the contrary, green supply chain performance management focuses on metrics concerned with green image and environmental issues [10]. With the advent of environmental concerns associated with manufacturing operations, the metrics and indicators for supply chain performance management have been expanded significantly. Given the wide scope of the possible metrics and the variety of supply chain strategies that can be implemented, a guiding framework is essential for effective understanding of performance measurement systems, specifically for the green supply chain.

In light of these issues, our approach seeks to provide a more detailed taxonomic analysis of performance measurement, deriving from our contributions on strategic green supply chain management (GSCM) and PMSs. As such, this study goes a step further to consider the context of specific green strategies and the appropriateness of 
specific performance measures. The study presents a taxonomic contingency framework which examines how different green strategies may be implemented and assessed in the context of specific PMSs. The specific objectives of this work are as follows:

(1) To perform a survey of case studies on green supply chain strategies and performance management systems;

(2) To develop a taxonomy of green strategies by analyzing the key drivers behind the adoption of specific green strategies;

(3) To develop an integrated framework for performance management for the green supply chain; and

(4) To suggest the most effective PMS metrics for the green supply chain, promoting understanding of green performance management systems.

The rest of the paper is organized as follows: The next section provides an overview of the research methodology and followed by the section which presents the results of literature search survey. An outline of green supply chain practices is presented in the fourth section. This is followed by a taxonomy of GSCM strategies in the fifth section. A framework for developing PMS is presented in the sixth section. Finally, concluding remarks and further research prospects are presented in the last section.

\section{Research methodology}

Green supply chain success indicators are quantifiers which are used in assessing the efficiency and effectiveness of green supply chain management practices. These indicators tend to vary between companies and industries, depending on their priorities and the focus of the performance criteria. The research methodology employed in this work considers existing empirical studies in the literature and seeks to coin a guiding platform for developing PMS in the context of specific green strategies. In this regard, the study consists of four phases, from literature survey through to framework development, as shown in Figure 1.

The first phase focuses on carrying out a literature search survey of real-world case studies on green practices and the implementation of relevant performance indicators. The aim is to figure out the drivers behind the implemented green practice and their influence on the performance indicators selected. The empirical studies were obtained through a wide search in academic studies, databases, and bibliographical lists so as to obtain the relevant information. Thus, the search was selected from published work in reputable journals, concerned with the implementation of green manufacturing strategies, such as Sustainability, Journal of Remanufacturing, International Journal of Production Economics, International Journal of Operations and Production Management, Supply Chain Management, Benchmarking: An International Journal, and Journal of Cleaner Production. The search criteria used included keywords such as 'green practices', 'green strategies', 'green supply chain', 'environmental issues', 'ecological', 'green supply chain performance measurement', 'performance indicators' and 'performance metrics'. The second phase highlights the critical areas of focus of each case study in order to determine the major driving elements behind the implementation of GSCM strategies. This would assist in answering questions as to why certain strategies are suitable for specific industrial contexts, and what was the performance measurement focus for each 


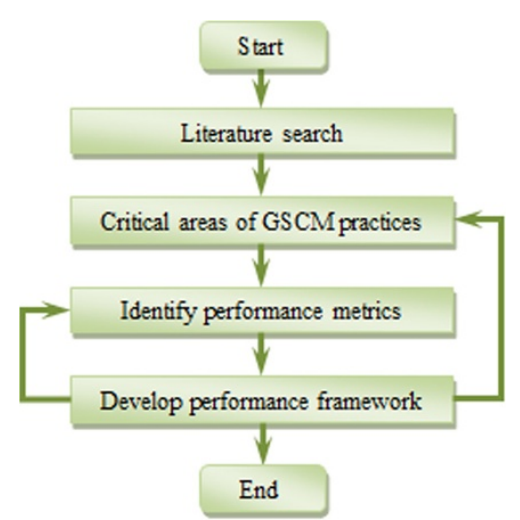

Figure 1 Research methodology.

industrial context. The third phase seeks to highlight green performance metrics chosen and the drivers behind the metrics chosen under different contexts of the case studies. The fourth and final phase aims to develop a generic framework for selecting the most appropriate PMS metrics for specific GSCM strategy.

In the next section, a summary of the outcome of the literature search survey is outlined.

\section{Results of the search survey}

The literature search survey indicated that some of the major contributors in the literature relevant to GSCM and PMS were Hart [13,14] and Porter and Van der Linde [15]. Other researchers in the area include Azzone and Noci [1], Kumar and Yamaoka [5], and Azzone et al. [6]. Following the literature search process, further perusal of selected publications also indicated that a number of organizations have embarked on introducing green practices. Some of these practices are green procurement, green product design, green production or manufacturing processes, green distribution, recycling and remanufacturing. For instance, Wal-Mart adopted green procurement of biodegradable and/or recyclable packaging. Automotive companies such as Toyota and Ford require ISO 14000 certification for their suppliers. Furthermore, it was realized that a number of firms have invested in recycling and reuse practices, for instance, Dell, Hewlett Packard, Toshiba and other electronics industries [16,17]. A number of legislations and regulatory systems are being put in place by governments and concerned stakeholders to account for environmental performance. In Western Europe, there is an obligation for $100 \%$ collection on 'white goods' [18]. The general acceptance of green activities has led to increasing empirical studies on the external and internal factors leading to the uptake of green practices and their impact on organizational performance [19]. Interesting results were also obtained with regard to the common trends in the development of performance measurement and management systems.

Table 1 provides a summary of the main areas of focus identified from the existing empirical studies investigated in this study. A closer look at the results of the literature search survey shows that there are three basic categories of areas of focus in green supply chains, namely (1) improving environmental performance, (2) improving economic 
performance, and (3) improving the firm's green image by promoting green initiatives that contribute towards the firm's social responsibility over the well-being of the society and its environment. The focus areas explain the need for developing performance indicators associated with each area. To measure, manage and control these areas of focus, it is crucial to establish appropriate performance indicators, and to put in place the necessary green strategies to enhance achievement of the desired goals within the respective areas. In retrospect, we can somewhat conveniently classify the performance indicators into the following:

(1) Environmental performance

(2) Economic or financial performance

(3) Social performance

Further explanations to the performance indicators in each of the above-mentioned category will be discussed in the 'Developing green PMS metrics' section. However, it is important to take a closer look at the green practices behind the focus areas.

\section{Green supply chain management practices}

In as much as several researchers have investigated the concepts of greening the environment at strategic and operational levels, many related researchers have studied greening practices, such as green product design [39,40], green process design [15,41], green purchasing [42] and green manufacturing practices at large [16,43,44]. From these greening concepts, the environmentally conscious practices, and the motive for organizational competitiveness, GSCM can be defined as follows:

$$
\begin{aligned}
\text { GSCM }= & \text { Green Purchasing }+ \text { Green Manufacturing }+ \text { Green Distribution } \\
& + \text { Green Reverse Logistics }
\end{aligned}
$$

Figure 2 shows the green practices in a closed loop green supply chain. Supply chain players such as used parts warehouses/storages, waste collectors, recycle plants, final

Table 1 Identified empirical studies on the GSCM performance

\begin{tabular}{lll}
\hline Area of focus & Performance metrics & Reference source \\
\hline 1. Environmental performance & Air emissions & {$[1,20-24]$} \\
& Waste water or water pollution & {$[7,8,11,21,22,24-26]$} \\
& Solid waste or hazardous materials & {$[21,22,27-32]$} \\
& Energy usage or consumption & {$[21,22,29,33,34]$} \\
2. Economic performance & Reverse logistics costs & {$[24,35-38]$} \\
& Sustainability costs & {$[8,11,23,26,37]$} \\
3. Social responsibility performance & Energy consumption costs & \\
& Green image & {$[8,23,26,27,29,30]$} \\
& Customer perspective & {$[8,11,17,23,26,27,30,32,36]$} \\
\hline
\end{tabular}




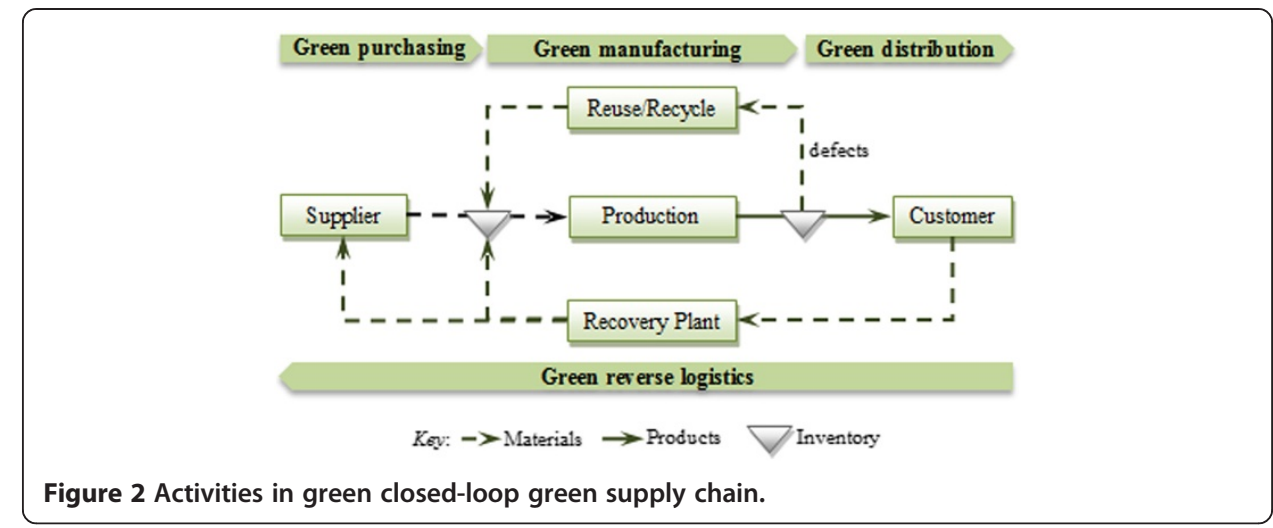

treatment (landfill) and other stakeholders are involved in carrying out these green activities.

\section{Green purchasing practices}

These are concerned with purchasing environmentally friendly materials and products, certification of potential suppliers, total quality environmental management (pollution prevention, internal performance measurement and auditing), environmentally friendly packaging and distribution [42]. Material recovery, reuse, and recycling are put in place so that all purchasing procedures satisfy environmental quality standards [45-47].

\section{Green manufacturing practices}

Green manufacturing defines efficient product design and production processes that use inputs with low environmental impacts, capable of producing minimal or no waste nor pollution $[39,40]$. Green product design ensures that the number of components in a product is minimized, assembly and disassembly processes are simplified, and material recovery, reuse and recycling are enhanced. In addition, green manufacturing consists of environmentally friendly processes that minimize raw material usage, energy usage, wastes, and emissions. The end result of green (re)manufacturing is reduced material costs, energy costs, occupational safety expenses, as well as improved production efficiency and corporate image.

\section{Green distribution practices}

Green distribution involves the application of green packaging practices that encourage the use of standard downsized packaging, recyclable materials, returnable packaging methods, and promotion programs on recycling and reuse [46,47]. In addition, green distribution encourages the use of energy-efficient distribution methods that minimize energy usage, carbon emissions, and transportation costs.

\section{Green reverse logistics}

Green reverse logistics is the process of retrieving the product materials or parts from the end user (consumer) in order to recapture value or dispose the materials in an environmentally friendly manner [46-48]. Green reverse logistics include activities such as 
waste collection, parts collection, inspection, selection, sorting, direct recovery, reprocessing, redistribution, and disposal [49,50]. Recovering products, refurbishing goods, and salvaging parts such as precious metals that can be recycled or reused can bring a huge benefit to the environment and to the manufacturer [50,51].

In light of the above, the choice and the success of these green practices depend on the strategies and capabilities of an organization. We present a taxonomic analysis of green strategies in the next section.

\section{GSCM strategies}

The adoption of green strategies has a far-reaching and multi-dimensional impact on performance [1]. In particular, the introduction of GSCM strategies may result in (i) management complexities due to changes in logistics for product recovery and recycling, leading to (ii) multiple changes in performance measurement, and in the management of operations at large. It is therefore imperative to identify the conditions under which these strategies are best implemented, and to analyze the performance measurement systems in light of the specific green strategies [45]. A question then arises as to what influences the selection and implementation of green strategies.

\section{Drivers behind green supply chain strategies}

The environmental awareness of an organization will influence the perspective from which green strategies are developed [45]. In the absence of environmental awareness, an organization adopts a naive perspective where the enterprise takes no initiatives towards improving environmental performance. In this work, two categories of GSCM drivers are identified: internal and external drivers. Internal drivers are as follows:

- Eco-efficiency perspective: Green strategies are developed with the objective of reducing wastes and resource usage, while maximizing environmental performance [52];

- Competitive advantage perspective: Green strategies are used as means of attaining a competitive advantage through product and process technology innovation [53];

- Ecological and ethical perspective: Green strategies are driven by the desire to reduce the industrial impact on the natural environment, rather than by the desire to improve on economic performance $[51,54]$.

Various researchers have identified total quality control, cost control, communities and environmental regulations as the main drivers behind an organization's environmental perspective $[45-48,55,56]$. However, from a broader view, the influence of such factors depends on a combination of factors at industry, country and even global levels. In addition to the above-mentioned internal drivers, we further identify the following external drivers:

- Compliance perspective: The need to comply with current environmental regulations forces adoption of green strategies; 
- Supply chain relationship: Supply chain collaboration and relationship will always influence the company's environmental behavior. For example, automotive companies require ISO 14000 certification for their suppliers.

- Green pressures: 'Green' movements arising from customers and other stakeholders lead to a widespread adoption of green strategies across the supply chain.

The drivers (internal and external) highlighted above are vital for the analysis of green supply chain strategies. In our investigation, it was observed that the selection of green strategies depends largely on a combination of internal and external drivers. For instance, a firm which is highly concerned with ecological and ethical responsibilities, located in a collaborative supply chain environment tends to choose closed-loop supply chain strategies (see Figure 3).

\section{The green supply chain strategies}

In view of the above internal and external drivers, we distinguish four major categories of GSCM strategies:

(1) Compliance-cantered,

(2) Lean-based,

(3) Innovation-cantered, and

(4) Closed-loop strategies.

Of the four green strategies, compliance-centered is the most basic with the closedloop strategy being the most complex. The adoption of the compliance-centered strategy is mostly due to external pressures while the implementation of the remaining three is mostly due to internal drivers. Organizations can thus start adoption of GSCM practices starting from the compliance-centered strategy and moving on to adopt the remaining strategies in turn until finally adopting the closed-loop strategy. Should any organization choose to fully implement a higher level green strategy, some of the green practices pertaining to lower strategies have to be implemented, as the starting point. In terms of performance measurement of each strategy, the higher level strategies contain all the performance indicators from the lower level strategies. In other words, adoption of the lean-based strategy allows the firm to also meet the requirements of the compliance-centered strategy.

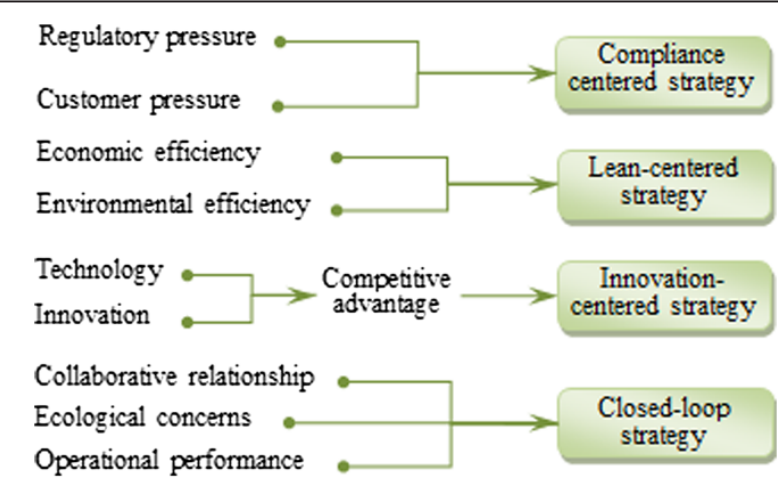

Figure 3 The main drivers behind closed loop supply chain strategies. 


\section{Compliance-centered strategy}

This strategy is adopted in response to environmental regulations, pressures from customers and other stakeholders such as government and green pressure groups [57]. Companies may be obliged to adopt international standard systems such as ISO 14001 [50], and purchasing contracts with suppliers aimed at meeting certain regulatory requirements. The strategy is mainly adopted by companies whose main objective is to comply with the requirements of their stakeholders, as a way of getting permission to do business (regulatory compliance) and qualifying to do business with relevant organizations (inter-organizational compliance). Companies adopting compliance-centered strategy are reactive to events and tend to view changes needed for compliance as a burden. Typically, these companies' investment to the greening of the supply chain is minimal [48]. The compliance-centered strategy is the most basic of the GSCM strategies and it is therefore the natural starting point for GSCM strategy implementation, and it requires minimal customer-supplier engagement.

\section{Lean-based strategy}

This is a more complex GSCM strategy normally adopted by organizations that focus on eco-efficiency or lean and green approach to GSCM. With this strategy, additional to meeting the requirements of the compliance-centered strategy, suppliers are required to satisfy certain operation-based efficiency targets. The strategy thus links environmental performance with operational efficiency through waste minimization and optimal resource usage $[19,44]$. The environmental performance benefits from this strategy arise from the adoption of specific manufacturing practices which are focused on resource use reduction and waste minimization, and in so doing also provide secondary environmental performance benefits. The lean-based strategy requires higher levels of customer-supplier engagement and it ties environmental performance to operational processes in the supply chain. To ensure economic benefits, all firms participating in the supply chain have to adopt lean-based operational process. This strategy is widely implemented within the automotive industry where automakers expect their suppliers to adopt sustainable lean-based operational processes, which are focused on waste minimization and resource use reduction.

\section{Innovation-centered strategy}

This is adopted by companies whose objective is to keep up-to-date with changes in environmental regulations through specialized technologies, product designs, processes and strict green performance standards $[16,50]$. The strategy requires organizations to adopt a product life-cycle perspective when developing their products, and give stricter environmental requirements to their suppliers. The organizations adopting this strategy routinely support their suppliers to modify their operational processes in order to meet the requirements of the newest environmental regulations. Participating organizations integrate specific relevant green activities, such as green design and green purchasing in order to improve current processes and product development. The strategy compels organizations to cultivate innovative capabilities to GSCM practices. Customer-supplier engagement is higher than that in lean-based strategy. The strategy is widely adopted in the automotive industry, an example being Chrysler Corporation [58]. 


\section{Closed-loop strategy}

This strategy is adopted by firms in highly collaborative supply chains where companies can keep abreast with complex requirements of closed-loop supply chain and to integrate with suppliers, from design to product take-back [59]. Material recovery, recycling and remanufacturing improve environmental performance of the entire supply chain $[24,36]$. This strategy is the most complex and collaborative type of GSCM strategy. It targets eco-efficiency achieved by the management of all processes in the supply chain that focuses on customer service level, which covers from raw materials to product delivery to customers, through design, procurement, production, distribution, use, reuse and disposal, product take-back, reverse logistics, including aspects such as reduction of time and resource use, costs and environmental impacts.

The strategy thus links the environmental performance to the entire supply chain activities and allows the integration of business goals pertaining to economic and operational performance, social performance and environmental performance. Organizations adopting this strategy require high levels of control over the capture and return of used materials. Of the four GSCM strategies, the closed-loop strategy requires the highest level of customer-supplier engagement. An example of companies adopting this strategy is Toyota Motor Corporation and its suppliers [60]. As an example, to increase its vehicle recycling performance, Toyota formulated the Toyota Recycling Vision in 2003 , whose target is to achieve a vehicle recovery rate of $95 \%$ by 2015 . The company achieved the target ahead of time in 2007 , and went on to achieve a vehicle recycling rate of $99 \%$ in 2011 [61].

\section{Developing PMS for the green supply chain}

To develop an effective green PMS for the green supply chain, the decision maker needs a guide or framework for developing the PMS and for identifying appropriate green performance indicators. There are four basic requirements that should be considered when developing an effective performance measurement system that can support green supply chain performance [1]:

- Strategic focus: the ability of the PMS system to account for the long-term impacts;

- Measurability: the ease of measurement, to enable assessment of green efficiency;

- Completeness: ability of the PMS to account for all relevant performance indicators;

- Timeliness: the amount of time taken by the PMS to collect and analyze the performance related data.

To effectively meet these requirements, there are critical areas of concern which supply chain decision makers should focus on. As identified from various empirical studies in the literature, critical success factors for every PMS in a green supply chain include (i) top management commitment, (ii) the availability of diagnosis tools, (iii) the ability to formulate an appropriate action plan deriving from the findings of the diagnosis, (iv) the availability of suitable performance measurement indicators, and (v) the availability of a performance management system for performance monitoring and improvement. The commitment of top management is imperative; this essentially calls for an establishment of a performance management function consisting of members in the top management, 
not forgetting the concerned operational managers. In addition, the availability of appropriate diagnosis tools is essential for quantitative and qualitative measurement of the supply chain performance. Deriving from the findings from diagnosis and analysis activities, appropriate action plans can then be formulated. However, to enable the supply chain decision maker to evaluate and monitor performance and effectiveness of the action plans taken, the availability of a set of efficient and effective performance measures/indicators is crucial. Above all, the availability of a performance management system is critical in order to monitor and improve the performance of the green supply chain. Based on these observations, a green performance management framework can be formulated.

\section{PMS development framework}

Figure 4 provides a framework for the development of green performance management systems, consisting of five phases: (1) developing a performance management function, (2) diagnosis and analysis, (3) developing an action plan, (4) developing a performance measurement system, and (5) developing a performance management system. These are explained in the following sections.

\section{Phase 1: GSCM performance function}

Proper management of the performance of the green supply chain requires commitment and focus from top management. A dedicated organizational structure must be set up to facilitate the performance improvement effort. Depending on the supply chain's needs, size, and characteristics, this structure can be in two basic forms: (a) a performance management unit, headed by an environmental performance manager who reports directly to senior management or (b) a cross-functional team comprising performance coordinators appointed from the concerned operational units.

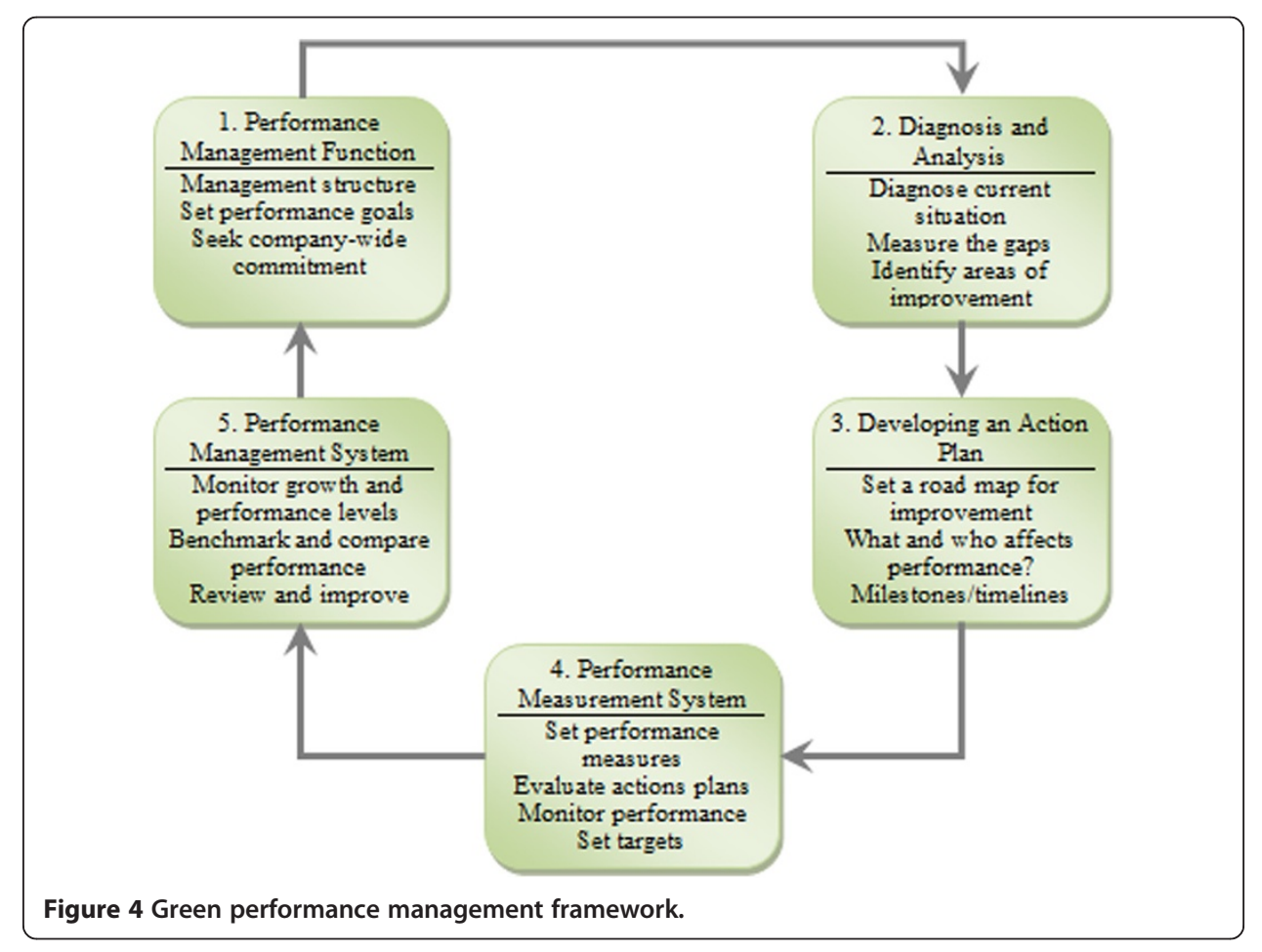


Phase 2: diagnosis and analysis

For any green performance-related intervention to be effective, one should have a thorough understanding of the current situation of the supply chain. This is done through a performance diagnosis to assess the supply chain's position, pinpoint its strengths and weaknesses, and recommend areas for improvement. A green performance diagnosis covers (a) a qualitative assessment of the supply chain performance in relation to the green levers and (b) a quantitative assessment of the supply chain performance based on certain key indicators or measures that are linked to the various selected green levers.

\section{Phase 3: developing an action plan}

After completion of the diagnosis step, the next step is to develop an action plan or a road map based on the findings obtained. The road map helps to direct specific activities towards the desired green performance goals in a systematic manner. The performance action plan is expected to address the following questions: What affects green performance? Who affects green performance? When should the activities be undertaken?

\section{Phase 4: performance measurement system}

Performance improvement initiatives must be complemented by a sound measurement system. The measurement system forms an integral part of the supply chain's performance management system. A sound measurement system consists of performance indicators that are useful for (i) monitoring environmental, economic, and social performance, (ii) setting performance targets, and (iii) developing appropriate supply chain strategies, or improving existing strategies.

\section{Phase 5: performance management system}

A performance measure informs the supply chain decision maker on how and why the supply chain is performing at a specific rate, and what it should do in view of its current performance. The next step is to use these indicators to manage green performance. Overall, performance management covers two main areas: (a) activities to monitor performance and (b) activities to reinforce performance across the supply chain. However, it is important to emphasize that the effectiveness of these activities hinge on the underlying system of performance metrics developed in the previous phase. As such, the next section deliberates on developing a system of green performance metrics.

\section{Developing green PMS metrics}

It has been noted that, when developing a system of green performance indicators, one should take into account the critical requirements, including [1] (i) strategic focus, the ability of the system of indicators to account for long-term investment decisions and their impacts; (ii) measurability, the ease with which measurement and assessment of green efficiency can be done; (iii) completeness, the ability of the performance system to account for all the relevant performance indicators for effective assessment of the firm's PMS; (iv) timeliness, so as to enable evaluation of the time taken by the PMS to 
analyze the collected data; and (v) cost of analysis, concerned with the cost of the resources needed to implement the PMS chosen.

Based on the characteristics of specific green strategies outlined in the taxonomy, PMS models can be developed to enhance the strategic focus and its measurability, while considering a judicious trade-off between completeness, timeliness, and cost of the performance measurement activities.

Environmental performance indicators (measures) are the core requirements of a PMS for effective evaluation of the environmental performance of processes, activities, and services of the supply chain. The taxonomy of green strategies assists the supply chain managers in identifying the most effective performance measures and in designing the most suitable PMS structure. Performance indicators range from air emissions to energy recovery and recycling. Possible PMS designs include (i) models which use physical indicators to describe environmental impact resulting from the strategy adopted, (ii) models based on economic indices linked with economic efficiency, (iii) models based on life-cycle analysis methods indicating the economic and physical impact of a given strategy throughout the product life cycle, and (iv) models based on an integrated perspective that indicates the effect of the adopted green strategy on shareholders' value, physical indices, and economic indices. The following section analyses performance metrics for the green strategies identified in this study $[4,5,11]$. To assess the impact of industrial processes, three categories of indicators are utilized:

(1) Physical indicators - to measure, in physical terms, how the supply chain activities affect the natural environment, or

(2) Economic or financial indicators - to measure the variation of the life-cycle costs associated with the product in question, or

(3) Social indicators - to measure the green image of a firm based on customer or stakeholder's evaluation.

In the most ideal case, effective PMSs should basically include both physical and economic indicators in an integrated framework. While physical indicators provide a timely assessment of the activities of the supply chain, economic or financial indicators indicate how the adopted supply chain activities affect the individual organization's profitability [4]. Therefore, an efficient PMS supporting the implementation of a green strategy should consider the physical environmental indicators, which express the organization's environmental performance. These indicators can be aggregated into the following categories [5]:

- Volume indices: These assess the amount of solid wastes resulting from a firm's production operations, such as percentage of scrap, and percentage of recyclable products;

- Process efficiency indices: These assess the environmental efficiency of a company's operations regarding waste water, air emissions and energy consumption.

- Design efficiency indices: These measure the 'green' design features defining the 'green' products, such as assembly time, number of materials or parts in a product, and number of levels in the bill of materials. 
In order to monitor the firm's contribution to economic or financial value creation in the supply chain, a set of carefully selected economic features need to be considered. These features can be classified into the following categories:

- Operational efficiency: costs of green manufacturing operations, materials, (non) manufacturing overheads, direct labor, and environmental compliance audits;

- Distribution costs: costs due to transportation, waste disposal and product take-back;

- Price of the product as well as demand for the product.

Suggested indicators and their descriptions are provided in the next sections.

\section{Indicators for compliance-based strategies}

The compliance-based strategy normally arises from the introduction of environmental regulations, governmental regulations, and extreme customer pressure [57]. The strategy seeks to identify the key areas of concern in line with the organization's capabilities, leading to the adoption of operations that ensure that the organization meets the required environmental performance. In this connection, the adopted PMS should offer the following:

- Timely measurement of physical indices to highlight the firm's performance;

- Accurate monitoring of physical indices in order to monitor the trend of the performance

Air emissions, waste water, solid wastes and energy consumption indicators should be included in the PMS in accordance with regulations. Table 2 shows the suggested indicators and their descriptions. For environmental performance assessment, the most effective way is to benchmark the current performance with the regulation standards. When selecting among different potential solutions or programs, an aggregate indicator, derived from the above indicators, can be used to evaluate the solutions. Thus, four indicators derived from these indicators can be used to describe the trends in environmental performance. Specialized indices can be aggregated into these four basic categories.

The identified indicators can be used to evaluate a decrease of various costs: (a) costs associated with material usage, energy usage, raw material usage and (b) costs associated with fees paid for waste discharge, waste treatment, including transportation and distribution. These are concerned with process efficiency indices.

The compliance-based PMS is most suitable to organizations that choose to follow a passive approach to environmental performance with the objective of introducing green concepts in order to meet customer pressure, or to comply with some limiting

Table 2 Compliance-based performance indicators

\begin{tabular}{lll}
\hline No. & Indicator & Description \\
\hline 1 & Air emissions & Percentage of gas emissions into the air, e.g., chlorinated pollutants \\
2 & Waste water & Percentage of pollutants in water, e.g., total nitrogen \\
3 & Solid waste & Percentage of materials sent for disposal \\
4 & Energy & Amount of energy consumed, e.g., electricity, oil \\
\hline
\end{tabular}


environmental regulations. One notable negative impact of this perspective is that it offers limited competitive advantage in the presence of aggressive innovations in environmental performance. Due to its reactive nature, the passive approach often lags behind the target performance required, resulting in loss of market share. In this regard, timeliness of the PMS is crucial, especially in the presence of fast-changing regulations and customer pressures.

\section{Indicators for lean-based strategies}

Lean-based strategies go beyond regulatory compliance through the requirement for the suppliers to meet operation-based targets. This strategy maximizes on economic performance while simultaneously providing secondary environmental performance benefits through waste and resource use reductions. The main objective of this strategy is to gain dual environmental and economic performance benefits. Therefore, when developing performance indicators for lean-based strategies, the following categories of measures should be included, if the strategies are to succeed $[53,54]$ :

- Physical indicators and

- Economic indicators

The physical indicators correspond to the compliance-based indicators listed in Table 2 in the previous section. In addition to this, lean-based economic performance indicators suggested in this study are summarized in Table 3.

\section{Indicators for innovation-based strategies}

The innovation-based strategies often lead to the introduction of new and complex green product and process technologies. These complex initiatives need complete and timely assessment techniques, usually with less attention on cost disadvantages, if any. Innovationcentered indicators seek to measure such factors as life cycle of product components, and number of assemblies or number of parts in a product. In this view, the set of performance indicators suitable for this strategy should include the following categories:

- Physical indicators,

- Economic indicators, and

- Innovation-specific indices

Further to the indicators defined in Tables 2 and 3, the PMS should also include indicators concerned with product life, product green efficiency, and green image. Indicators

Table 3 Lean-based economic indicators

\begin{tabular}{lll}
\hline No. & Indicator & Description \\
\hline 1 & Material costs & Decrease of materials purchasing costs \\
2 & Energy & Decrease of energy consumption costs \\
3 & Inventory costs & Decrease of inventory (storage) costs \\
4 & Waste treatment & Decrease of fees paid for waste treatment \\
5 & Waste discharge & Decrease of fees paid for waste discharge \\
6 & Transportation & Decrease of transportation related costs \\
\hline
\end{tabular}


defining product life show how long a product, or its components, can be used. This evaluation is crucial for long-term forecasting of energy and material usage. Table 4 presents a summary of innovation-based indicators.

\section{Indicators for closed-loop strategies}

Performance indicators for the closed-loop supply chain range from air emissions to energy recovery and recycling indices. Possible designs include (i) physical indicators to describe environmental impact resulting from the green manufacturing activities, (ii) economic indices linked with economic efficiency, (iii) life cycle analysis methods indicating the economic and physical impact of the supply chain throughout the product life cycle.

In a collaborative supply chain environment characterized by integrated relationships, innovative initiatives such as product take-back and take-back of recyclable end-of-life materials can easily be supported through involvement of suppliers [62]. In this vein, life cycle assessment is an appropriate model that should be implemented. This enables the organization to measure the environmental impacts of the product over its entire lifecycle, right from collection of raw materials and design to recovery and/or disposal. The life cycle analysis model can be used to assess the impact of the industrial processes using: physical, economic, and social indicators. Hence, in addition to the compliancebased indicators (Table 2), the lean-based indicators (Table 3), and the innovation-based indicators (Table 4), the closed-loop strategy should include the social or ecological performance indicators as well.

Table 5 provides a list of suggested indicators for measuring social performance of a supply chain. These indices include green image, which is a measure of the customers' perspective due to the firm's green practices such as product take-back, recycling, and product recovery. Such activities have a positive impact on the firm's green image from the perspective of the society.

\section{Conclusions and further research}

In every supply chain context, with specific green strategies, it is essential to select or develop appropriate PMS, if the system is to be effective. This research proposed a structured approach to guide supply chain managers who intend to develop effective PMS for specific GSCM strategies.

\section{Managerial implications}

The motivation for the adoption of GSCM practices varies across different organizations. Most organizations adopt GSCM practices due to external pressures, and in most cases, the level of adoption is at the baseline level, that is, they only meet the minimum requirements [63]. This problem is mostly brought about by the difficulty in justifying

Table 4 Innovation-based performance indicators

\begin{tabular}{lll}
\hline No. & Indicator & Description \\
\hline 1 & Product Life & Life cycle of different product components or sub-assemblies \\
2 & $\begin{array}{l}\text { Product green } \\
\text { efficiency }\end{array}$ & $\begin{array}{l}\text { Increase of green design features in a product; number of parts, number of } \\
\text { materials, etc }\end{array}$ \\
3 & Green image & Increase in customer goodwill due to addition of innovative greening activities \\
\hline
\end{tabular}


Table 5 Indicators for social performance

\begin{tabular}{lll}
\hline No. & Indicator & Description \\
\hline 1 & Percent recycling & Increase in recycled material compared to material disposal \\
2 & Product green efficiency & Increase of green design features in a product; number of parts, etc \\
3 & Green image & Increase in customer goodwill due to greening activities \\
\hline
\end{tabular}

the economic benefits for the adoption of GSCM practices [29]. Due to a lack of robust performance measurement systems, it is hard to quantify the tangible benefits derived from the adoption of different GSCM practices. This study provides a systematic way of developing performance indicators to allow the consistent quantification of the benefits of adoption of different GSCM practices, across the four green strategies. The taxonomic approach and the measurement techniques presented in this study provide operational guidelines for devising a set of performance indicators that are suitable for the selected green strategy. In this regard, the approach is applicable across various supply chain domains. In addition, the framework can be used to evaluate the possible available green options when changing from one green strategy to the other. For instance, when changing from compliance-centered to innovation-centered strategy, new indicators that pertain to the contribution of the enterprise's innovative product and process technologies should be designed.

Since the adoption of higher level green strategies requires that an organization satisfactorily meets the requirements of lower level strategies, the GSCM framework can be used as a basis of a maturity model for GSCM practices. Organizations can thus use the model to assess their level of adoption of GSCM practices. For example, are they at the stage of compliance-centered or lean-based?

The GSCM framework, through the four strategies, also provides a basis for benchmarking performance against other firms, and enhances inter-organizational relationship $[62,63]$. Additionally, the framework can be used as a basis for supplier selection - a firm can decide to work with organizations at a specific level of GSCM strategy adoption, e.g. lean-based strategy.

\section{Further research}

Further research directions include the validation of the application of green performance indicators for each PMS identified in this research. This will help to establish the validity of the indicators or the metrics for green supply chain performance measurement across different categories of green strategies. Furthermore, new comprehensive or hybrid indicators may be designed for integrated assessment of both environmental and economic performance.

Competing interests

The authors declare that they have no competing interests.

\section{Authors' contributions}

MM contributed in developing the concept of context-specific performance measurement systems under various supply conditions and objectives, derived the structured approach to developing green performance management systems, and made a draft of the paper. HM contributed in further analysis of case studies and the performance metrics used in specific contexts. RM contributed in further literature search survey, critical revision of the paper for practical relevance. All authors read and approved the final manuscript. 


\section{References}

1. Azzone, G, Noci, G: Identifying effective PMSs for the deployment of "green" manufacturing strategies. Int. J. Operations Produc. Manag. 18(4), 308-335 (1998)

2. Azzone, G, Bertele, U: Exploiting green strategies for competitive advantage. Long Range Plan. 27, 69-81 (1994)

3. Bloom, GS, Morton, MS: Hazardous waste is every managers' problem. Sloan Manage. Rev., $75-84$ (1991).

4. Noci, G: Supporting decision making for recycling based investments. Bus. Strateg. Environ. 4(2), 62-71 (1995)

5. Kumar, S, Yamaoka, T: System dynamics study of the Japanese automotive industry closed loop supply chain. J. Manuf. Technol. Manag. 1(2), 115-138 (2007)

6. Azzone, G, Bianchi, R, Mauri, R, Noci, G: Defining operating environmental strategies: programmes and plans within Italian industries. Environ. Manag. Health 8(1), 1-15 (1997)

7. Hervani, AA, Helms, MM, Sarkis, J: Performance measurement for green supply chain management. Benchmarking Int. J. 12(4), 330-353 (2005)

8. Gunasekaran, A, Patel, C, Tirtiroglu, E: Performance measures and metrics in a supply chain. Int. J. Operations Product. Manag. 21, 71-87 (2001)

9. Brewer, PC, Speh, TW: Adapting the balanced scorecard to supply chain management. Supply Chain Manage Rev. 5(2), 48 (2001)

10. Beamon, BM: Measuring supply chain performance. Int. J. Operations Product Manag. 19, 275-292 (1999)

11. Gray, R: Accounting and environmentalism: an exploration of the challenge of gently accounting for accountability, transparency and sustainability. Acc. Organ. Soc. 17(5), 399-425 (1992)

12. Chan, FTS, Qi, HJ: An innovative performance measurement method for supply chain management. Supply Chain Manag. 8, 209-223 (2003)

13. Hart, SL: A natural-resource-based view of the firm. Acad. Manag. Rev. 20(4), 986-1014 (1995)

14. Hart, SL: Beyond greening: strategies for a sustainable world. Harv. Bus. Rev. 75(1), 66-76 (1997)

15. Porter, M, Van Der Linde, C: Green and competitive: ending the stalemate. Harv. Bus. Rev. 28(6), $120-134$ (1995)

16. $\mathrm{Hu}, \mathrm{AH}, \mathrm{Hsu}, \mathrm{CW}$ : Empirical study in the critical factors of green supply chain management (GSCM) practice in the Taiwanese electrical and electronics industries. IEEE Int. Conf. Manage. Innov. Tech., 853-857 (2006)

17. $\mathrm{Hu}, \mathrm{AH}, \mathrm{Hsu}, \mathrm{CW}$ : Critical factors for implementing green supply chain management practice-an empirical study of electrical and electronics industries in Taiwan. Manage. Res. Rev. 33(6), 586-608 (2010)

18. Vlachos, D, Gaorrgiadis, P, lakovou, E: A system dynamics model for dynamic capacity planning of remanufacturing in closed-loop supply chains. Comput. Oper. Res. 34, 367-394 (2007)

19. Simpson, D, Samson, D: Developing strategies for green supply chain management. Decision line. 39(4), 12-15 (2008)

20. Agarwal, G, Vijayvargy, L: Green supplier assessment in environmentally responsive supply chains through analytical network process. Proceed. Int. Multi. Conference Eng. Computer Sci. Hong Kong. 2, 14-16 (2012). 1-6

21. Kainuma, Y, Tawara, N: A multiple attribute utility theory approach to lean and green supply chain management. Int. J. Prod. Econ. 101(1), 99-108 (2006)

22. Zhu, Q, Sarkis, J, Lai, K: Confirmation of a measurement model for green supply chain management practices implementation. Int J Product Econ 111, 261-273 (2008)

23. Zhu, Q, Sarkis, J, Lai, K: Initiatives and outcomes of green supply chain management implementation by Chinese manufacturers. J. Environ. Manag. 85, 179-189 (2007)

24. Olugu, EU, Wong, KY, Shaharoun, AM: A comprehensive approach in assessing the performance of an automobile closed-loop supply chain. Sustainability 2, 871-889 (2010)

25. Chia, A, Goh, M, Hum, S: Performance measurement in supply chain entities: balanced scorecard perspective. Benchmarking Int. J. 16(5), 605-620 (2009)

26. Tsoulfas, GT, Pappis, CP: A model for supply chains environmental performance analysis and decision making. J. Clean. Prod. 16, 1647-1657 (2008)

27. Olugu, EU, Wong, KY, Shaharoun, AM: Development of key performance measures for the automobile green supply chain. Resour. Conserv. Recycl. 55(6), 567-579 (2011)

28. Eltayeb, TK, Zailani, S, Ramayah, T: Green supply chain initiatives among certified companies in Malaysia and environmental sustainability: Investigating the outcomes. Resour. Conserv. Recycl. 55, 495-506 (2011)

29. Li, Y: Research on the performance measurement of green supply chain management in China. Int. J. Sustain. Dev. 4(3), 101-107 (2011)

30. Rao, P, Holt, D: Do green supply chains lead to competitiveness and economic performance? Int. J. Operations Product Manage. 25, 898-916 (2005)

31. Rao, P: Greening of the supply chain: a new initiative in South East Asia. Int. J. Operations Product Manage. $22,632-655(2002)$

32. Mclntyre, K, Smith, H, Henham, A, Pretlove, J: Environmental performance indicators for integrated supply chains: the case of Xerox Ltd. Supply Chain Manag. 3, 149-156 (1998)

33. Wu, J, Dunn, S, Forman, H: A study on green supply chain management practices among large global corporations. J. Supply. Chain Operations Manag. 10(1), 182-194 (2012)

34. Wang, HF, Gupta, SM: Green supply chain management-A product life cycle approach. McGraw-Hill Prof. Med/Tech., (2011)

35. Choudhary, M, Seth, N: Integration of green practices in supply chain environment - the practices of inbound, operational, outbound and reverse logistics. Int. J. Eng. Sci. Technol. 3(6), 4995-4993 (2011)

36. Mondragon, AEC, Lalwani, C: Measures for auditing performance and integration in closed-loop supply chain. Supply Chain Manage. Int. J. 16(1), 43-56 (2011)

37. Diabat, A, Govindan, K: An analysis of the drivers affecting the implementation of green supply chain management. Resour. Conserv. Recycl. 55(6), 659-667 (2011) 
38. Olugu, EU, Wong, K: A study on the validation of green supply chain performance measures in the automotive industry. Commun. IBIMA, 2011, 1-14 (2011)

39. Gupta, M: Environmental management and its impact on the operations function. Int. J. Operations Product. Manag. 15(8), 34-51 (1995)

40. Allenby, B: Supporting environmental quality: developing an infrastructure for design. Total Qual. Environ. Manag. 2(3), 303-308 (1993)

41. Klassen, RD, McLaughlin, CP: The impact of environmental management of firm performance. Manag. Sci. 42(8), 1199-1215 (1996)

42. Handfield, R, Walton, SV, Sroufe, R, Melnyk, SA: Applying environmental criteria to supplier assessment: a study in the application of the analytical hierarchy process. Eur. J. Oper. Res. 141, 70-87 (2002)

43. Winsemius, P, Guntram, U: Responding to the environmental challenge. Bus. Horiz. 35(2), $12-20$ (1992)

44. Mutingi, M, Mbohwa, C: A taxonomic framework for developing green supply chain strategies. Proceed. 2012 Int. Conference Ind. Eng. Operations Manag. Istanbul Turkey 6, 326-335 (2012)

45. Korchi, AE: Conditions of emergence of OEM's reverse supply chains. J. Remanufactur. 4(3), (2014). doi:10.1186/ 2210-4690-4-3

46. Srivastava, S: Green supply-chain management: a state-of-the-art literature review. Int. J. Manag. Rev. 9(1), 53-80 (2007)

47. Tibben-Lembke, RS: Life after death: reverse logistics and the product life cycle. Int. J. Phys. Distr. Log. Manag. 32, 223-244 (2002)

48. Van Hoek, Rl: From reversed logistics to green supply chains. Supply Chain Manag. 4, 129-134 (1999)

49. Schot, J, Fischer, K: Environmental Strategies for Industry: International Perspectives on Research Needs and Policy Implications. Island Press, Washington D.C (1993)

50. Kollman, K, Prakash, A: EMS-based environmental regimes as club goods: examining variations in firm-level adoption of ISO 14001 and EMAS in U.K., U.S., and Germany. Policy. Sci. 35(1), 43-67 (2002)

51. CRR: The Centre for Remanufacturing and Reuse. (2014). http://www.remanufacturing.org.uk/. Accessed 15 July 2014

52. Ninlawan, C, Seksan, P, Tossapol, K, Pilada, W: The implementation of green supply chain management practices in electronics industry. Proceed Int. Multi-Conference Eng. Computer Sci. 3, (2010)

53. Azzone, G, Noci, G: Measuring the environmental performance of new products: an integrated approach. Int. J. Prod. Res. 34(11), 3055-3078 (1996)

54. Sarkis, J, Rasheed, A: Greening the manufacturing function. Bus. Horiz. 38(5), 17-27 (1995)

55. Diabat, A, Kannan, D, Mathiyazhagan, K: Analysis of enablers for implementation of sustainable supply chain management: a textile case study. J. Clean. Prod. 14(5), 1-13 (2014)

56. Zhu, Q, Sarkis, J: An inter-sectoral comparison of green supply chain management in China: drivers and practices. J. Clean. Prod. 14, 472-486 (2006)

57. Zhu, Q, Sarkis, J, Geng, Y: Green supply chain management in China: pressures, practices and performance. Int. J. Operations Product Manag. 25(5), 449-468 (2005)

58. Braun, J, Guthrie, M, McCampbell, E, Sit, V: Chrysler Corporation: Innovations In Supply Chain Management, Case Study. University of Michigan. (1997). Available from: http://www-personal.umich.edu/ afuah/cases/case3.html. Accessed 03 August 2014

59. Beamon, BM: Designing the green supply chain. Logist. Inf. Manag. 12(4), 332-342 (1999)

60. Lopes, CP, Lobato, AM, Akabane, GK, Mendonca, C, Soares, WLP, Barreto, RM: Toyota motor European (TME) sustainable logistics: An example to Brazil. POMS 21st Ann. Conf. Vancouver Canada (2010)

61. Toyota Motor Corporation: Vehicle Recycling, Sustainability Report. (2014). Available from: http://www.toyotaglobal.com/sustainability/report/vehicle_recycling/pdf/vr_all.pdf. Accessed 07 August 2014

62. Lind, S, Olsson, D, Sundin, E: Exploring inter-organizational relationships in automotive component remanufacturing. J. Remanufactur. 4, 5 (2014)

63. Zhu, Q, Sarkis, J, Kai, K: Green supply chain management: practices and performance within the Chinese automobile industry. J. Clean. Prod. 15, 1041-1052 (2007)

doi:10.1186/s13243-014-0006-z

Cite this article as: Mutingi et al.: Developing performance management systems for the green supply chain. Journal of Remanufacturing 2014 4:6.

\section{Submit your manuscript to a SpringerOpen ${ }^{\circ}$ journal and benefit from:}

- Convenient online submission

- Rigorous peer review

- Immediate publication on acceptance

- Open access: articles freely available online

- High visibility within the field

- Retaining the copyright to your article

Submit your next manuscript at $>$ springeropen.com 